\title{
EL DISCURSO DE LAS REMESAS COMO IMPULSORAS DEL DESARROLLO Y LA AGENCIA COLECTIVA DEL MIGRANTE COLECTIVO*
}

MATT BAKKER**

RESUMEN: Este artículo explora la relación entre líderes de clubes de oriundos, y funcionarios, tanto del gobierno mexicano como de los organismos financieros globales, en la promoción de "proyectos productivos» que pudieran crear empleo en las comunidades expulsoras de migrantes, convirtiendo así la migración en una «opción» en vez de una «necesidad». Combina un análisis del contenido de textos fundamentales de un naciente discurso de "remesas para el desarrollo» con entrevistas a fondo con los líderes de la Federación de Clubes Zacatecanos del Sur de California (FCZSC) y sus organizaciones hermanas en el área de Los Ángeles, funcionarios del estado de Zacatecas y políticos migrantes en Zacatecas. Utilizando estos materiales, el artículo explora los momentos de discordia entre la retórica neoliberal orientada hacia el mercado, en contra del Estado en el que se fundamenta el discurso oficial, y la(s) imaginación(es) políticas de los líderes de la FCZsC. El argumento que se presenta es que estos momentos de discordia sugieren que la relación entre los líderes de la FCZSC y los portadores del discurso de remesas al desarrollo es distinto a la cooptación de los clubes y federaciones. Sin embargo, se concluye que las interpretaciones comunes de las prácticas del "migrante colectivo», que las ven como necesariamente transformadoras, son prematuras. Se propone, como alternativa, la idea de que los nuevos sujetos sociales son construidos políticamente, por lo que al crear alternativas radicalmente democráticas se requerirá

\footnotetext{
* Una versión anterior de este artículo se publicó con el título «The Social Construction of «Migrant-led Productive Investment»» en el libro en prensa Citizenship Across Borders: The Political Transnationalism of "El Migrante», que escribí en coautoría con Michael Peter Smith. Agradezco a Cornell University Press por su permiso para publicarlo aquí nuevamente. Este artículo se presentó originalmente en el Segundo Coloquio Sobre Migración y Desarrollo realizado en Cocoyoc, Morelos en octubre de 2006. Agradezco a los organizadores del Coloquio la invitación a presenter mi trabajo ahí, además de los muchos participantes en el Coloquio que hicieron comentarios al texto. Agradezco, además, a Michael Peter Smith, Luis Guarnizo, y Ming-cheng Lo por sus detallados comentarios a versiones previas de este artículo. Finalmente, también quisiera agradecer al dictaminador anónimo de Migración y Desarrollo, cuya crítica y sugerencias ayudaron a mejorar el artículo. Por supuesto que se aplican las advertencias acostumbradas y cualquier limitación que contuviera el artículo será mi responsabilidad exclusiva.

** Universidad de California, Davis.

Nota Del editor: Traducción del inglés por Luis Rodolfo Morán Quiroz.
} 
tender lazos a través de las múltiples divisiones sociales que fracturan la colectividad migrante.

PALABRAS CLAVE: Remesas; Zacatecas; migrante colectivo; cooptación; agencia.

ABSTRACT: This article explores hometown association leaders» growing engagement with state officials and the international financial community in pursuit of job-creating "productive projects» in migrant-sending communities that might help to convert Mexican migration from a «necessity» to an "option». It combines a content analysis of key texts expressing an emergent «remittances-to-development» discourse with elite interviews with leaders of the Federación de Clubes Zacatecanos del Sur de California (FCZSC) and related organizations in Southern California, as well as with Zacatecan state officials and return migrant politicians in Zacatecas. Drawing upon this data, the article explores the moments of discordance between the market-oriented, anti-statist neoliberal rhetoric of the official remittances-to-development discourse and the political imagination(s) of the FCZsc leaders. I argue that these moments of discordance suggest that the FCZsC leaders» engagement with the purveyors of the remittances-to-development discourse is more than simple cooptation. However, I conclude that common interpretations of the practices of the "collective migrant» as necessarily transformative are premature. Working from the belief that new social subjects are political constructions, I argue that the process of building more radically democratic alternatives will require explicit linkages to be forged across multiple lines of social difference that currently divide the migrant collectivity.

KEY WORDS: Remittances; Zacatecas; the collective migrant; cooptation; agency.

\section{INTRODUCCIÓN}

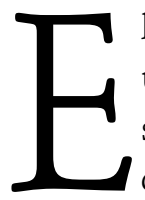
1 monto de las remesas enviadas a América Latina y el Caribe durante la última década ha tenido un notable crecimiento. La recepción de remesas en México se ha disparado en este periodo, de un total de poco menos de $\$ 3.7$ miles de millones en 1995, a más de \$23 mil millones en 2006 (Banco de México, 2007). Para 2004, México recibía en remesas una cantidad superior a la del total enviado a todos los países de América Latina y el Caribe -incluido el propio México- en el año de 1999 (Lozano Ascencio, 2004).

A medida que las transferencias monetarias de los migrantes se han incrementado, ha crecido el interés de las instituciones financieras globales -entre ellas el Banco Mundial, el Fondo Monetario Internacional, el Banco Interamericano de Desarrollo- así como su esfuerzo por generar instrumentos de política para canalizar las remesas en direcciones que fortalezcan el "potencial para el desarrollo» de esos flujos. Como consecuencia de esta difundida atención, surge un consenso importante entre los estados expulsores de migrantes, las fundaciones filantrópicas y las instituciones financieras globales sobre la trascendencia de las remesas para estimular empresas que generen ingresos en las regiones de origen, -consenso que aquí denomino el «discurso del desarrollo impulsado por las remesas» (remittances-to-development discourse).

No es de sorprender que este discurso forme parte del contexto político-económico vigente, en el que se hace énfasis en los mecanismos del mercado. Esta orientación hacia el mercado también ha influido el discurso de la relación entre 
las remesas y el desarrollo, insertándolo en un amplio abanico de propuestas de política y de documentos promulgados por los estados y las instituciones internacionales que se analizarán más adelante. Es importante decir, sin embargo, que el discurso de las remesas como impulsoras del desarrollo, basado en las premisas neoliberales, sitúa el potencial del desarrollo impulsado por las remesas en el empresario migrante en cuanto individuo, así como en el mercado. Este discurso promueve una visión ambiciosa de la "democracia financiera», en el que los cambios impulsados por el mercado, incluidos el mercado formal y las industrias de transferencia monetaria, ofrecen convertir en empresario a cada migrante pobre y a cada individuo receptor de las remesas. Al mismo tiempo, varias organizaciones de migrantes han empezado también a centrarse en las contribuciones que pueden realizar para promover el «desarrollo» en sus comunidades y regiones de origen.

Tomando como base estos dos discursos, este artículo analiza la interacción de una de esas organizaciones, la Federación de Clubes Zacatecanos del Sur de California (FCZSC), con sede en el sur del estado de California, EEUU, y compuesta por organizaciones de migrantes mexicanos provenientes del estado de Zacatecas, con el aparato global orientado al desarrollo. Parte de la premisa: en la medida que cobró importancia el papel de las remesas de los migrantes en el discurso oficial de la relación entre remesas y desarrollo, en años recientes, los líderes de las asociaciones de oriundos (Hometown Associations-HTA) reunidas en la FCZsc han participado, cada vez más, con actores vinculados al estado en Zacatecas y con la "comunidad filantrópica» internacional en la promoción de inversiones orientadas a la creación de empleos en sus lugares de origen, impulsadas por las remesas. Este objetivo establecido recientemente por la FCZSC es una transformación significativa respecto a los proyectos sociales y de infraestructura que las HTAs que la constituyen solían impulsar en décadas pasadas. Esos proyectos, sin embargo, permitieron a los líderes de la FCZSC relacionarse y negociar con funcionarios de los ámbitos municipal, estatal y federal del gobierno mexicano. Esta nueva opción permite a los líderes de las HTAs, que son los principales protagonistas de mi relato, contar con una gama más amplia de relaciones que las establecidas en años precedentes. ¿̇Cómo entender la creciente imbricación de los líderes de la FCZSC con funcionarios de distintos niveles de gobierno, la comunidad financiera internacional y el discurso neoliberal sobre la relación entre las remesas y el desarrollo? En términos más simples ìse trata de nuevos mecanismos de cooptación o estas formas de colaboración implican algún nivel de negociación entre visiones alternativas de la migración y el desarrollo?

\section{SOBRE LA CONSTRUCCIÓN POLÍTICA DE LA SUBJETIVIDAD DEL MIGRANTE COLECTIVO}

Con frecuencia, la capacidad de agencia de los migrantes internacionales se asocia a su potencial liberador y se le concibe como una especie de desafío contra-hege- 
mónico a los estados-nación y a la globalización neoliberal (Kearney, 1991; Rodríguez, 1996; Portes, 1998). A pesar de los llamados pioneros de Guarnizo y Smith para tener cautela con tan festiva colección de imágenes y para realizar análisis más detallados de la «dialéctica de la dominación y de la resistencia» en el estudio del transnacionalismo, las representaciones festivas del «transnacionalismo desde abajo» siguen influyendo en las ciencias sociales (Guarnizo y Smith, 1998: 6).

En el caso mexicano, la investigación reciente sobre el surgimiento del «migrante colectivo» ha tratado el tema de la naturaleza transformadora de la migración transnacional (Delgado y Rodríguez, 2001, 2002; Moctezuma, 2002, 2003, 2005; Delgado, Márquez y Rodríguez, 2004; Delgado, 2006). El concepto del migrante colectivo se originó con el trabajo pionero de Miguel Moctezuma, por lo que sus textos merecen una atención particular. Desde el punto de vista teórico, el concepto parte del sofisticado intento de Moctezuma por problematizar la investigación sobre el transnacionalismo migrante, llevándolo del enfoque basado en aspectos simbólicos de identidad y cultura, hacia un plano más material, en el que hace énfasis en aspectos como la membresía y la práctica activa de los migrantes en múltiples puntos de un espacio social transnacional emergente.

Moctezuma (2005: 6) define al migrante colectivo como un «sujeto social transterritorial [emergente] comprometido, binacionalmente, en luchas por la identidad, la democracia y por el desarrollo comunitario y regional». El migrante colectivo, argumenta este autor, asume diversos grados de conciencia social que al tiempo que lleva a un mayor ejercicio del poder de los migrantes, le permite un cuestionamiento de las formas tradicionales de poder. En el mismo trabajo, el migrante colectivo es concebido como un sujeto que surge solamente después de que el proceso migratorio ha atravesado por una serie de etapas de crecimiento y desarrollo. En ella, las redes translocales y las «comunidades filiales» son los elementos constitutivos de las primeras formas del transnacionalismo migrante. Con el tiempo, a medida que estas formas de conexión translocal se consolidan, comienza a formalizarse el sentido de pertenencia y de obligación de los migrantes hacia sus comunidades de origen, lo que podría ser el cimiento de los clubes sociales de los migrantes o de las asociaciones de oriundos (Moctezuma, 2005).

A medida que avanza este proceso de crecimiento, las HTAs pueden ir más allá de una identidad y una práctica puramente translocales, evolucionando hasta llegar a las formas más avanzadas de organización de los migrantes, la asociación -o federación- de las HTAs (Moctezuma, 2003, 2005). Es precisamente en esta etapa, la más avanzada, cuando el migrante colectivo surge como un nuevo «sujeto social transterritorial». Este nuevo sujeto es concebido como «un subproducto contradictorio del desarrollo histórico y de la maduración de las redes migratorias» (Delgado, 2006: 41) que, al adoptar formas de organización cada vez más formales, «fortalece los lazos de la identidad cultural, de pertenencia y solidaridad con las comunidades de origen» (Delgado y Rodríguez, 2002) y puede «convertirse en un sujeto clave en las cuestiones relacionadas con el desarrollo regional» (Moc- 
tezuma, 2002). En algunas formulaciones, el migrante colectivo se representa como iniciador de caminos alternativos, los cuales, aunque incipientes, ponen en duda el modelo hegemónico neoliberal de la integración norteamericana (Delgado, 2006).

El concepto de migrante colectivo y las tipologías relacionadas ${ }^{1}$ resultan analíticamente útiles para distinguir entre distintos tipos de migrantes. Estas distinciones son, sin lugar a dudas, importantes para evaluar el potencial de desarrollo impulsado por los migrantes y también para diseñar políticas públicas dirigidas a estimularlo. ${ }^{2}$ Sin embargo, es necesario tener cuidado con la aplicación del concepto migrante colectivo en los análisis del ámbito político.

Los teóricos del migrante colectivo reconocen que su nuevo sujeto social transterritorial representa apenas una pequeña fracción de la población migrante (Moctezuma, 2005), aún cuando ésta sea la más «dinámica, decisiva y organizada» (Márquez, 2006a: 326). No obstante estas acotaciones, creo que la formulación del migrante colectivo tiene muchas similitudes con el concepto de comunidad transnacional formulado tempranamente por autores como Portes (1998), aunque, sin lugar a dudas, también hay diferencias importantes entre estos dos conceptos. A mi juicio, una de las diferencias más evidentes es que el migrante colectivo es concebido como un sujeto social cuyas formas de identidad, membresía y práctica política trascienden los límites de una simple comunidad translocal. Esto añade, sin duda, un importante nivel de complejidad a los análisis previos de los aspectos políticos de las comunidades transnacionales. A pesar de sus diferencias, la conceptualización del migrante colectivo y la de comunidad transnacional se asemejan en el hecho de que ambas se basan en una noción esencialista de la identidad colectiva y la formación de comunidades. Mientras el concepto de comunidad transnacional evoca una imagen idílica de relaciones comunitarias igualitarias y homogéneas, el de migrante colectivo se presenta como una unidad coherente que actúa incuestionablemente a favor de la población migrante más amplia, de las redes sociales, comunidades filiales y clubes sociales a partir de las cuales surgió. Esta visión, sin embargo, no contempla las importantes líneas de demarcación existentes dentro de la colectividad migrante, líneas que dificultarían cualquier intento de unificar sus intereses bajo una sola identidad política, cualesquiera que ésta sea.

Como ha señalado Guarnizo (1998) sobre la formulación original de comunidad transnacional, los conglomerados que resultan de la migración transnacional contemporánea están fracturados por las divisiones internas de clase, étnicas, de género, políticas y regionales. De ahí que, en vez de fundamentarse en el tema idílico de la comunidad, sugiere que estos conglomerados se conciban como «formaciones sociales transnacionales» (Guarnizo, 1998). Dadas estas desigualdades

\footnotetext{
1 Véase Moctezuma, 2002 para elaboraciones más detalladas.

2 En este sentido, véase Goldring, 2004 quien realiza un análisis articulado de los diferentes tipos de remesas de los migrantes, su lógica interna y las alternativas de política pública.
} 
y divisiones internas que fracturan a las colectividades migrantes, la invocación de migrante colectivo como un agente social y político unificado resulta problemática especialmente en lo que se refiere a la constitución de las asociaciones de migrantes como sujetos potencialmente transformadores, que cuestionan la globalización neoliberal y las formas tradicionales de poder (Moctezuma, 2005; Delgado, 2006).

El punto a resaltar aquí no consiste en afirmar que la construcción de un sujeto migrante unificado sea una tarea imposible. La idea es impulsar una formulación de migrante colectivo siguiendo líneas construccionistas de lo social, insistiendo en que la formación de un sujeto migrante unificado sólo puede darse como resultado de la práctica política y la lucha ideológica. Tal formulación se distingue claramente de la conceptualización actual del migrante colectivo en donde este sujeto emerge de manera casi natural, a partir de la evolución de las organizaciones migrantes.

Analizar al migrante colectivo dentro de un enfoque construccionista de lo social requiere una atención más plena de los proyectos políticos e ideológicos que construyen los migrantes activistas. Si bien, los trabajos recientes han captado vívidamente el crecimiento de las HTAs y sus cada vez mas complejas estructuras organizacionales (Moctezuma, 2005; Rivera-Salgado, Bada y Escala, 2005; Lanly y Valenzuela, 2004; Rivera y Escala, 2004; Bada, 2003), las afirmaciones respecto al potencial transformador del migrante colectivo no han encontrado apoyo en evidencias empíricas sustantivas que documenten el contenido real de los proyectos ideológicos y de las prácticas políticas de los migrantes. Esta falta de atención al contenido ideológico de las prácticas políticas de los activistas de las asociaciones de migrantes representa una limitante significativa en los análisis académicos contemporáneos debido a que el significado de esas prácticas no puede derivarse del contexto material de su surgimiento, ni del proceso de evolución de las organizaciones. Esta limitante resulta particularmente problemática en el momento presente porque, a primera vista, la participación de los líderes de las asociaciones de migrantes en proyectos de colaboración con el estado neoliberal mexicano y los diversos órganos de la llamada comunidad filantrópica internacional podría fácilmente percibirse como evidencia de una conclusión marcadamente divergente.

Los estudios académicos recientes sobre la globalización neoliberal han explicado el crecimiento del sector de las onGs y las consecuencias de las actividades de ese sector como intentos de las élites globales y nacionales para construir una "cara comunitaria del neoliberalismo» (Petras, 1997: 11; véase también, Petras y Veltmeyer, 2001; Dolhinow, 2005; Yaworsky, 2005). Se puede extender este tipo de análisis a las actuales actividades de las HTAs y sus asociaciones. Al hacerlo, el trabajo de las asociaciones de migrantes se ha interpretado por algunos no como una práctica transformadora, sino como su polo opuesto -como funcional al pro- 
yecto neoliberal, al difundir el conflicto social y ofrecer legitimidad política a la práctica neoliberal de la descentralización (Márquez, 2006a, 2006b, 2006c).

Es imposible dejar de considerar que en el momento actual, el neoliberalismo constituye el contexto institucional e ideológico en el que se define cualquier relación con el Estado, sean estos funcionarios públicos o realización de proyectos. De ahí que simplemente por participar en programas de colaboración con funcionarios públicos, fundaciones internacionales e instituciones financieras globales, los activistas de las asociaciones de migrantes se han convertido, en un sentido u otro, en "agentes del neoliberalismo». Sin embargo, no existe una justificación intelectual para descalificar esta colaboración, a partir de este argumento. En mi opinión, esa interpretación sólo puede sostenerse basándose en una distinción tajante entre una lucha completamente autónoma o la cooptación total.

Los activistas migrantes estudiados aquí muestran las limitaciones de esa distinción. No se trata de personas que por su ingenuidad política o cultural obedezcan ciegamente los dictados de actores y fuerzas poderosas. Como muestro más adelante, estos activistas están impulsados por sus propias esperanzas, deseos y sueños; en pocas palabras, los arreglos de colaboración con funcionarios públicos o agencias internacionales resultan de complejas negociaciones con una diversidad de actores sociales e intereses, e implican, al mismo tiempo, una actividad como agentes mucho más intensa de lo que podría pensarse con la simple noción de cooptación.

Del mismo modo, sería igualmente problemático atribuir un potencial transformador a las prácticas de los activistas migrantes transnacionales de manera acrítica. La articulación de los intereses políticos de los migrantes no necesariamente constituye un desafío directo a los discursos hegemónicos, las estructuras de la desigualdad y las constelaciones de poder que las perpetúan. El valor político de la práctica migrante -y la de todos los demás sujetos sociales y políticossiempre son una cuestión empírica que no puede leerse directamente de las condiciones materiales o de la posición estructural en la economía política global (Mouffe, 1979; Laclau y Mouffe, 1985; Hall, 1996).

De ahí se deriva la necesidad de un acercamiento a los aspectos culturales y políticos de la migración transnacional, que se centre en el contenido real de las identidades y de los intereses políticos que los migrantes construyen en el curso de sus vidas cotidianas. Este tipo de acercamiento implica necesariamente un análisis de las herramientas ideológicas de las que echan mano los migrantes para darle significado a su situación actual y generar estrategias para el futuro. Este artículo se propone elaborar sobre ese análisis, al centrarse específicamente en los aspectos culturales y políticos del desarrollo guiado por los migrantes. Para hacerlo, adopto una perspectiva teórica orientada hacia la agencia (Smith, 2001), capaz de explorar la forma en que los activistas migrantes interpretan, se comprometen $y$, a veces, se resisten al actual discurso hegemónico neoliberal sobre el conjunto de problemas de la migración y el desarrollo. 
Para abordar este análisis, me baso en una variedad de fuentes cualitativas, que resulta de más de una docena de entrevistas a profundidad a los líderes de la FCZSC y organizaciones relacionadas en el sur de California, así como a algunos funcionarios del estado de Zacatecas y a migrantes de retorno dedicados a la política en Zacatecas. Estas entrevistas fueron realizadas como parte de un proyecto más amplio sobre la construcción de la ciudadanía migrante transnacional entre Estados Unidos y México, elaborado en colaboración con Michael Peter Smith. Las entrevistas se complementan con datos etnográficos recolectados por medio de observación participante en varios lugares del sur de California y de Zacatecas, así como con materiales de archivo que incluyen documentos oficiales de esos estados en los países mencionados y de una gama de documentos de fundaciones e instituciones financieras internacionales.

Aunque el tipo de materiales de investigación cualitativa recolectados para este proyecto se utiliza con frecuencia para abordar temas teóricos en un nivel estrictamente micro, vale la peña señalar desde ahora que este trabajo es más ambicioso. Este proyecto sigue un método de estudio de caso extenso que, vinculado con la discusión teórica, intenta relacionar las observaciones hechas en el nivel micro y los datos de las entrevistas, con fuerzas, conexiones e imaginaciones transnacionales y globales más amplias con las que se conectan lo global y lo local (Burawoy, 2000) en las vidas cotidianas de los sujetos de esta investigación.

Los sujetos etnográficos reunidos en este artículo son particularmente adecuados para realizar este trabajo de etnografía transnacional porque dichos sujetos, como individuos, están constantemente ligados en la práctica y el imaginario de la vida transnacional, además de constituirse como unos de los activistas migrantes transnacionales más prominentes del planeta. De esta manera, estos agentes cuentan con conexiones transfronterizas construidas a través de su participación en una multiplicidad de redes sociales y políticas, que van desde las trans-localidades que se forman entre sus pueblos de origen y los del sur de California, hasta los corredores de poder en Sacramento o Washington, D.C., pasando por los circuitos de las élites políticas y financieras mundiales. Estas redes les aportan una amplia visión de las posibilidades y desafíos políticos que resultan de esta era globalizadora.

El artículo se estructura de la siguiente manera: primero, se analiza el discurso de las remesas y su relación con el desarrollo, según se despliega en la esfera transnacional de Estados Unidos y México, así como en los modelos de política diseñados por el Banco Interamericano de Desarrollo. En la siguiente sección se examina el giro de la FCZsC hacia la promoción de proyectos productivos generadores de empleos y financiados por los migrantes en Zacatecas. Esta sección enfatiza la forma en que los líderes migrantes zacatecanos imaginan su rol en el desarrollo, los obstáculos que enfrentan para su realización, así como las políticas y prácticas necesarias para superar estos obstáculos. En este apartado se hace énfasis en los momen- 
tos de discordancia entre el discurso oficial de las remesas basado en la retórica neoliberal y la imaginación política de los líderes de la FCZsC. En la sección final del artículo se revisan las cuestiones teóricas planteadas a fin de evaluar las disyuntivas del «desarrollo impulsado por los migrantes» en la teoría y en la práctica.

\section{LA DECONSTRUCCIÓN DEL "DISCURSO DE LAS REMESAS ORIENTADAS AL DESARROLLO»}

En el contexto de la relación México-Estados Unidos, el contenido del discurso de las remesas orientadas al desarrollo quizá encuentre su mejor ilustración en la agenda del Acuerdo para la Prosperidad firmado por los presidentes Vicente Fox y George Bush en el año 2001. Esta sociedad se anticipaba como un vehículo para «promover el crecimiento en las regiones menos desarrolladas de México... aprovechando el poder de los libres mercados para impulsar el bienestar social y económico de los ciudadanos, en particular en las regiones en donde el crecimiento económico se ha retrasado y ha desatado la migración» (Partnership for Prosperity, 2002). En este acuerdo, se pensaba que una vía clave para cumplir con esta meta sería estimular la competencia en la industria de los servicios de las remesas, a fin de reducir los costos y atraer a más migrantes a las instituciones bancarias formales («hacer que quienes no usen el banco comiencen a hacerlo» o banking the unbanked, según el término oficial).

El discurso de Vicente Fox en el foro «Compromisos con el Paisano: Remesas y Servicios» en 2001, ilustra la manera en que se concibe, en el lado mexicano, el espacio transnacional Estados Unidos-México y la idea de que las remesas se convertirían en una importante herramienta de desarrollo. Tras confirmar su creencia en la «libertad de emprender», Fox sugirió que su gobierno buscaba ampliar el Programa $3 \times 1$ a nivel federal de modo que:

las inversiones y las transferencias que envían nuestros paisanos no sólo vayan al consumo, como sucede actualmente, sino ahora vayan destinados a inversiones en sus comunidades, pero también vayan destinados a inversiones en proyectos productivos (...) proyectos productivos de los cuales serán dueños y accionistas los propios paisanos y lo serán sus familiares en sus comunidades; proyectos productivos que permitirán financiar y generar las fuentes de empleo que se requieren para poder arraigar a los jóvenes que vienen en camino. (Presidente de México Vicente Fox, 3 de marzo de 2001).

Este lenguaje, claramente orientado al mercado, ofrece una demostración de la forma en que el gobierno mexicano percibe a los migrantes mexicanos que viven en el extranjeroy del tipo de compromiso que pretende establecer con ellos. Dejando atrás la «política de no política» (García y Griego, 1988, citado en Martínez, 
1998), durante los tres últimos regímenes presidenciales, el gobierno mexicano ha establecido un conjunto coherente de políticas para la reincorporación de los migrantes, que buscan capitalizar los recursos políticos, sociales y económicos de los mexicanos cuyas vidas se desarrollan del otro lado de la línea divisoria del Río Bravo/Río Grande. El lenguaje de Fox deja claro, además, la profundidad con la que estas políticas de reincorporación de los migrantes se han combinado con el proyecto ideológico neoliberal. Vistos a través de la óptica neoliberal del Estado mexicano, los reclamos políticos y las preocupaciones sociales de los migrantes deben abordarse con la mediación del mercado y de la «iniciativa privada»; a su vez, ellos y la familia que se queda en la comunidad de origen son interpelados no como ciudadanos, sino como potenciales inversionistas y accionistas en proyectos productivos capaces de generar oportunidades de empleo, deteniendo la migración y, en el proceso, transformando el papel histórico de estas comunidades como fuentes de mano de obra migrante para Estados Unidos.

Estos ejemplos demuestran el grado que ha alcanzado el fundamentalismo del mercado, que ubicado en el centro de la relación entre México y Estados Unidos, se ha extendido al ámbito de las relaciones entre el Estado y los transmigrantes. En estas acciones del Estado mexicano, la migración se muestra como un problema a remediar y, al aislar las causas de la migración dentro del ámbito económico, el desarrollo económico local se percibe como una medida mágica que disminuirá automáticamente los flujos migratorios. Estas importantes acciones de política ilustran claramente de qué manera las élites han construido al migrante como un sujeto neoliberal en el ámbito estatal. Si tan sólo pudieran incorporarse de manera efectiva y eficiente en los mercados financieros, los migrantes y sus remesas se convertirían en agentes del desarrollo neoliberal en sus regiones de origen y en portadores de un futuro post-migratorio.

Permítasenos ahora cambiar de escala para ver de qué manera el migrante y sus remesas se representan e incorporan en los esquemas de política del aparato global de desarrollo.

En el ámbito de las instituciones financieras globales, el Banco Interamericano de Desarrollo (BID) se ha convertido en el principal promotor para concebir y utilizar las remesas como "palanca de desarrollo». Desde principios del 2001, el BID, por medio de su Fondo de Inversión Multilateral (Fomin o Multilateral Investment Fund-MIF) ha trabajado en América Latina y el Caribe para promover una visión de las remesas de los migrantes para utilizarse como palanca de desarrollo en la región. A tal efecto, el Fomin encargó estudios y realizó congresos en el continente para discutir las remesas y su potencial impacto en el desarrollo, al tiempo que financió una diversidad de proyectos de alcance regional o nacional. Como consecuencia del intenso trabajo del banco en el área durante el último lustro, el programa de remesas del Fomin ha desarrollado un elaborado discurso acerca del papel y del impacto de las remesas para el desarrollo de las regiones de origen de los migrantes en países concretos. Este modelo se centra en una doble estrate- 
gia en la que los mercados financieros constituyen el medio crucial por el cual el FOMIN espera lograr sus metas: la primera estrategia es incrementar los recursos financieros disponibles para quienes reciben las remesas; la segunda consiste en incrementar el impacto de esas remesas en el desarrollo.

El discurso neoliberal orientado al mercado en el que se enmarca el programa de remesas del fomin, si bien se ha elaborado en un sinfín de documentos y estudios en los últimos años, ${ }^{3}$ probablemente se ilustra mejor en el documento «Remesas 2004: transformar los mercados de mano de obra y promover la democracia financiera. $»^{4}$ Este documento presenta de manera sucinta el aparato conceptual que rige el modelo discursivo del Fomin en torno al desarrollo impulsado por las remesas. Aunque el documento comienza con lo que podría leerse como una explicación marxista de la migración internacional -al afirmar, por ejemplo, que "la ecuación básica en el continente americano y en el mundo es muy simple: los países desarrollados requieren mano de obra migrante y las familias que se quedan en el terruño necesitan de las remesas (...) De manera tal que la gente se traslada por millones hacia el «norte» y el dinero se mueve hacia el «sur» en miles de millones» (Mif, 2005: 2)- esa explicación, entonces, se lleva hacia rumbos neoliberales. El proceso migratorio se presenta como profundamente empresarial, a medida que los migrantes «como los empresarios en busca de mercados en el mundo [atraviesan el globo] en busca de ventajas comparativas.» (Mif, 2005: 2).

Paradójicamente, el lenguaje del transnacionalismo se emplea para argumentar que a pesar del espíritu empresarial de los migrantes, «la fuerza impulsora es...el compromiso con los valores de la familia...Se trata de familias transnacionales que viven y contribuyen en dos países, dos economías y dos culturas a la vez.» (Mif, 2005: 2). Al reconocer los profundos efectos de estos flujos migratorios transnacionales en los mercados de mano de obra globales, el reporte hace énfasis en la necesidad de adoptar «nuevas reglas y mecanismos para hacer frente a las realidades modernas de la fuerza de trabajo migrante en los mercados de mano de obra mundiales.» (Mif, 2005: 2).

¿Qué significa esta vaga referencia a nuevas reglas y mecanismos? ¿Se trata de una señal a favor de la liberalización de las políticas de inmigración en el norte industrializado, una defensa de las fronteras abiertas? En esta receta neoliberal no se trata de eso. Esta convocatoria a nuevas reglas y mecanismos es una alusión directa al propósito de trasladar a quienes envían y reciben las remesas al sector bancario formal, lo que el reporte denomina democracia financiera. Tras determinar que tan sólo el 10\% de quienes reciben remesas tiene acceso a cuentas bancarias y otros servicios financieros, el reporte anticipa que al finalizar la década

\footnotetext{
${ }^{3}$ Para una muestra de estos, véase los reportes incluidos en la compilación de Terry y Wilson, 2005.

${ }^{4}$ Este documento ("Remittances 2004: Transforming Labor Markets and Promoting Financial Democracy») fue presentado en el congreso del BID/FOMIN titulado «El envío de dinero al terruño: el mapa del año 2004 de los flujos de remesas hacia América latina» («Sending Money Home: the 2004 Map of Remittance Flows to Latin America») realizado en Nueva York en marzo de 2005.
} 
«millones de personas pobres se integrarán en el sistema financiero y las remesas podrán ser aprovechadas a través de la vinculación de los flujos con las instituciones locales de microfinanciamiento, préstamos hipotecarios e incluso la seguridad de los bonos.» (Mif, 2005: 3).

Volviendo al énfasis puesto en el nivel individual/familiar, las remesas se presentan en el documento como «decisiones individuales que se realizan para el mayor beneficio de las familias» (Mif, 2005: 3). En la utopía neoliberal que se presenta en «Remesas 2004» el desafío para el FOMIN y sus colaboradores es simplemente dar a los migrantes y a sus familias «más opciones para el uso de su propio dinero.» (Mif, 2005: 3) porque, cuando los migrantes y sus familias tengan esas opciones, «ellos harán el resto.» (Mif, 2005: 3).

A pesar de estos utópicos pronunciamientos que ensalzan el espíritu empresarial individual de los migrantes, el Estado mexicano neoliberal y sus socios en las instituciones financieras globales se enfrentan con un problema fundamental: el reciente incremento en las remesas no ha conseguido reducir en una medida sensible la pobreza en México (Lozano y Olivera, 2005), mucho menos ha logrado que quienes reciben las remesas puedan disponer de una reserva de ingresos libres para el gasto o de ahorros que pudieran dirigirse a la inversión productiva. El reconocimiento de ese hecho básico ha obligado a los funcionarios del gobierno mexicano a establecer vínculos con las asociaciones de oriundos e intentar canalizar el capital social y económico colectivo de estas asociaciones hacia la inversión productiva generadora de empleo. Pero, żcómo se imaginan los activistas migrantes zacatecanos las posibilidades de un desarrollo impulsado por las remesas?

PERCEPCIONES DE LOS MIGRANTES DEL

«DESARROLLO IMPULSADO POR LOS MIGRANTES»

¿Qué ha hecho que los líderes migrantes del sur de California busquen cambiar sus actividades tradicionales de promover el «desarrollo de la comunidad» hacia «proyectos productivos» en sus comunidades de origen? ¿̇Esta visión del desarrollo impulsado por los migrantes es plenamente consistente con la visión neoliberal expuesta por el Estado, en Estados Unidos y en México, así como por las instituciones financieras internacionales, o existe alguna disonancia entre las visiones desde arriba y aquellas desde abajo?

\section{La migración como una opción más que como una necesidad}

En las entrevistas que realicé con Michael Peter Smith, para los zacatecanos del ámbito rural el objetivo de convertir la migración en una opción se presentaba con frecuencia como la razón principal por la cual los líderes migrantes promo- 
vían el giro hacia la inversión productiva. Parecería contradictorio para estos líderes migrantes, cuyas propias vidas se han enriquecido en su mayor parte a través del proceso migratorio, estar tan deseosos de reducir la oleada de la migración hacia el norte, considerando que, como fue reportado por los entrevistados, el liderazgo de la FCZSC está compuesto principalmente por migrantes (varones) de origen campesino y convertidos en empresarios exitosos en el sur de California.

Sin embargo, después de hacer un análisis detallado de sus descripciones sobre esta meta y de la experiencia migratoria en general, se puede explicar esta aparente contradicción. Consideremos las voces de Efraín Jiménez, director filantrópico de la FCzsc, Guadalupe Gómez, ex presidente de la federación y Martha Jiménez, una de las más activas mujeres líderes de la federación, quienes expresan una buena porción de la complejidad de sentimientos compartida por la mayor parte de los entrevistados:

[la migración] nunca se detendrá porque, por ejemplo, en Zacatecas es una forma de vida: te vas al norte... Es una forma de vida para buscar mejores oportunidades. Por eso la gente como nosotros viene para acá, porque allá no hay esperanza. ¿̇Por qué se vino mi papá a Estados Unidos? Porque el ganado se moría. Porque nunca llovía. Porque en Zacatecas necesitas bombardear las nubes con nitrógeno... Así que es por necesidad. (Entrevista con Martha Jiménez, Los Ángeles, California, 24 de marzo de 2005). Queremos generar una solución para los migrantes. Porque todos los zacatecanos vienen a Estados Unidos porque tienen que venir. Y no queremos eso. Queremos que ésa sea una opción, no una necesidad. Mire: para que un zacatecano se quede, de los que viven en Zacatecas, queremos que tenga la opción de venir a Estados Unidos si quiere venir... pero no por necesidad. Porque ahora tienen esa necesidad, no tienen opción, tienen que venirse para acá. (Entrevista con Efraín Jiménez, Los Ángeles, California, 13 de mayo de 2004, énfasis mío).

Me preocupa el futuro de nuestras comunidades en México. Y estamos preocupados por el futuro de México. Tenemos los recursos para desarrollar otro Canadá u otro país del que algún día podamos decir que sus ciudadanos viajan no porque tengan que hacerlo, sino (...) porque quieren. Quieren venir acá porque quieren ir a Disneylandia, porque quieren ir a Montaña Mágica. Ya ve, eso (...) tiene que ser algún día (...) ése sería el objetivo, el objetivo a largo plazo. (Entrevista con Guadalupe Gómez, Los Ángeles, California, 14 de mayo de 2004).

Estos fragmentos ilustran dos argumentos importantes que añaden una muy necesaria complejidad al reduccionismo económico del discurso de las remesas aplicadas al desarrollo utilizado por el gobierno mexicano y los organismos internacionales. En primer lugar, estas voces sugieren que la migración que proviene de Zacatecas se experimenta a la vez como una necesidad económica y como una expectativa comunitaria o rito de paso en las comunidades de origen de los migrantes. En segundo lugar, sugieren que incluso si tuviera éxito el desarrollo económico y la creación de empleos en las regiones mexicanas de origen de esos mi- 
grantes, esto probablemente no signifique un alto a la migración, ya que algunas personas continuarán optando por migrar en busca de las siempre escurridizas mejores oportunidades y los pastos más verdes que se representan en los mitos eternos del viaje al norte.

Es todavía más importante señalar que estos pasajes nos dan acceso a un subtexto que enfatiza el giro a la inversión productiva. El que estos migrantes no estén plenamente de acuerdo con la migración como estrategia de vida puede parecer sorprendente, ya que algunos de ellos constituyen el puñado proverbial de los migrantes mexicanos que logran el verdadero éxito económico en Estados Unidos y por ello, sostienen el mito de la migración. A pesar de esto último, expresan una ambivalencia hacia el proceso migratorio que traiciona cualquier visión no diferenciada de sus impactos en los individuos y comunidades.

La ambivalencia expresada hacia la experiencia de la migración, y hacia las diferentes oportunidades disponibles para los migrantes en Estados Unidos, encontró la más notable expresión en nuestra entrevista con Manuel de la Cruz, ex presidente de la FCZSC en Los Ángeles y actual diputado migrante por el Partido de la Revolución Democrática (PRD), de centro-izquierda, en el congreso del estado de Zacatecas. Comenzó con una lectura nacionalista de los peligros de la migración con rumbo a Estados Unidos:

México no tiene esa necesidad de enviar tanto migrante, de que tanta gente se salga. Hoy es una verdadera pena, es triste que nosotros lo hemos vivido (...) [uno] llega a Estados Unidos y (...) no tiene derechos. Trabaja y trabaja y todo lo que debe de ganar en beneficio (...) pues el gobierno de Estados Unidos se queda con él, cuando Estados Unidos no gastó un solo cinco en hacer esa fuente de trabajo. Ahora aquí cuando estudien, hay estudiantes muy sobresalientes, terminan su carrera y no tiene un trabajo. So, se van a Estados Unidos. iEso es terrible! iTremendo! خ̇ué nos espera de un país así como México en poco tiempo? Pos, irá mermando, irá acabando. iO llegará el momento en que seamos como Puerto Rico, carajo! (risas) iUn país asociado de Estados Unidos! (Entrevista con Manuel de la Cruz, Zacatecas, Zacatecas, 25 de junio de 2004).

Mas adelante, sin embargo, De la Cruz reconoce que: «Mis intereses están allá [en Estados Unidos] y aquí solamente está mi deseo de que México progrese (...) Allá están mis hijos, están mis casas, está todo y aquí está mi corazón (risas). ¿Qué puedes hacer? ¿̇ué puedo hacer?» (Entrevista con Manuel de la Cruz, Zacatecas, Zacatecas, 25 de junio de 2004).

Estos sentimientos contradictorios, quizá más amplificados en las representaciones discursivas del primer diputado migrante del estado, que como la mayor parte de los migrantes, dan fe de un legado, así como el continuado efecto del racismo, de la discriminación y de la exclusión que enfrentan los mexicanos en sus vidas cotidianas y en su participación en los asuntos políticos de Estados Unidos. Este lado oscuro de la experiencia migratoria contribuye a explicar por 
qué estos migrantes exitosos están tan inclinados a reducir la migración, a darles otras opciones a los migrantes potenciales.

Sin embargo, żcómo anticipan los líderes migrantes zacatecanos su deseada transición de la «migración como necesidad» a la «migración como opción»? i̇Cuáles son los obstáculos para lograrlo?

\section{Proyectos productivos: iel siguiente paso hacia el progreso?}

Los líderes de las HTAs están profundamente preocupados por el futuro de sus comunidades de origen; las actividades de sus clubes están, por definición, dirigidas al mejoramiento de esas comunidades, por medio de la construcción de infraestructura pública y la provisión de instalaciones urbanas más modernas. El éxito que han experimentado los líderes migrantes al crear el programa de fondos concurrentes entre los clubes y los distintos niveles de gobierno para financiar proyectos en sus comunidades de origen ha ayudado a impulsarlos hacia formas más amplias de participación en la comunidad.

Así, para los líderes de la FCZsC, su participación en las diversas versiones que ha tenido el Programa $3 \times 1$ tuvo consecuencias de mayor alcance, en la medida en que estos migrantes consolidaron un capital social y político que pudieron movilizar hacia otros propósitos. Goldring (2002: 70), por ejemplo, hace notar de qué manera la participación de los líderes de las HTAs zacatecanas en el Programa $2 \times 1$ los proveyó de una arena de interacción en donde los proyectos discursivos y políticos del transnacionalismo dirigido por los migrantes y el dirigido por el Estado entraron en conflicto entre sí. Este conflicto dio a los migrantes espacio para renegociar su relación con el Estado, tomando formas que desafían las tradicionales lecturas corporativistas y clientelistas de las relaciones entre el Estado y la sociedad en México.

Esto es así, porque el sentido de eficacia que se generó por los compromisos productivos entre las estructuras del Estado y los funcionarios del gobierno concedió poder a los líderes migrantes para actuar de maneras cada vez más políticas en otras esferas de sus vidas. Para la FCZSC, este empoderamiento permitió a algunos de sus líderes participar de manera más plena y explícita en política tanto en Estados Unidos como en Zacatecas, así como desarrollar una visión más amplia de las posibilidades y requerimientos de la contribución de los migrantes al desarrollo de la comunidad en su estado de origen.

El giro dado por la FCZsc hacia los proyectos de inversión productiva y de generación de empleos, aun cuando es claro que todavía es incipiente, refleja precisamente esa visión más amplia del desarrollo de la comunidad a medida que los líderes migrantes buscan ir más allá de simplemente contribuir a la infraestructura básica, los servicios urbanos y las instalaciones culturales y recreativas. 
El siguiente extracto de nuestra entrevista con Manuel de Cruz ilustra de qué manera los migrantes ven este paso más allá de los proyectos sociales:

Matt Bakker (MB): خ̇Entonces usted ve con buenos ojos la transformación o la transición que está haciendo la FCZsC de proyectos sociales a inversiones productivas?

Manuel de la Cruz (MD): Por supuesto. Porque el primer paso ya lo dimos. No puedes hacer un proyecto productivo cuando no tienes las vías de comunicación o el servicio básico, que es drenaje, agua potable, escuelas, clínicas. Pero si ya lo tenemos, ya lo hicimos.

$M B: \dot{Z}$ Entonces es como un segundo paso?

MD: Es el siguiente paso, el segundo paso es obligatorio iniciar y establecer proyectos productivos para seguir avanzando. No podemos quedarnos allí. No podemos dejar los pueblos solos, bellos. Eso no podemos. Para que nuestra gente ya no emigre o se quede allí, tiene que tener generación de empleos. (Entrevista con Manuel de la Cruz, Zacatecas, Zacatecas, 25 de junio de 2004).

A pesar de la retórica a la que recurre De la Cruz, no queda claro si los proyectos de colaboración entre los migrantes y el gobierno han dado el primer paso, creando las redes de comunicación y de infraestructura necesarios para atraer inversión y generar oportunidades de empleo, que puedan ayudar a cambiar la percepción de los zacatecanos sobre la migración como una necesidad. De hecho, Felipe Delgado -un líder migrante de larga trayectoria y quien sucediera a De la Cruz como representante oficial del gobierno zacatecano en Estados Unidoshabló con franqueza acerca de las dificultades que enfrentaba para atraer a los inversionistas hacia su estado a causa de las deficiencias en la infraestructura de transporte y comunicación. Por ejemplo, nos dijo Delgado, «las carreteras son más difíciles que en Estados Unidos. Es decir [imaginen] que están produciendo vidrio u otras mercancías como ésa (...) Tenemos que trabajar mucho para tener una infraestructura [como la que habría] en cualquier otra parte del mundo. Así que promuevo mi estado de diferentes maneras, pero es muy difícil.» (entrevista con Felipe Delgado, Los Ángeles, California, 13 de noviembre de 2003).

Esta voz, proveniente del gobierno de Zacatecas, identifica los obstáculos en la infraestructura que se oponen a que los inversionistas y las empresas creadoras de empleos se sientan atraídos a invertir allí. Más importante aún, resquebraja las representaciones utópicas de las remesas de los migrantes como una herramienta potencial de desarrollo. En el discurso oficial de las instituciones financieras internacionales y de los gobiernos de México y Estados Unidos, los problemas que enfrentan las regiones de origen de los migrantes son, en buena medida, consecuencia de falta de capital, lo que, en su visión, podría remediarse canalizando las remesas hacia el sector financiero formal y, eventualmente, hacia la inversión. Los líderes migrantes con los que hablamos, sin embargo, están plenamente concientes de los otros problemas y límites al desarrollo existentes en el contexto local que constituyen obstáculos para una economía sana, además de la escasez 
de capital. Los líderes migrantes no expresan el mismo optimismo que quienes diseñan las políticas desde arriba, en el sentido de que las causas económicas de la migración pueden resolverse simplemente a través de «los miles de millones faltantes» (Mif, 2005: 1) que, de repente, habían sido encontradas en las remesas de los migrantes, por los diseñadores de política en los ámbitos nacional e internacional.

Los tipos de obstáculos que identifican los líderes migrantes en el ámbito local abarcan un amplio abanico. Para algunos, la principal fuente de problemas lo constituye el ambiente regulatorio y de política en México que les parece poco claro y escasamente estimulante; un líder pesimista de la FCZsC por ejemplo, nos dijo que los clubes de migrantes zacatecanos (HTAs) todavía preferían los proyectos sociales a los proyectos productivos porque «las leyes no están claras [y] te cobran impuestos con base en tu inversión [no] en tus ganancias.» (entrevista con Felipe Cabral, Hawaiian Gardens, California, 15 de mayo de 2004).

Un tema recurrente en nuestras entrevistas con los líderes migrantes lo constituyó la dificultad que enfrenta el sector agrícola y campesino. Por supuesto que esto no habría de ser sorpresa alguna, ya que los productores medianos y pequeños en México han sido devastados por la liberalización del comercio y los recortes en los subsidios gubernamentales durante el periodo neoliberal. Empero, lo que resulta interesante es la divergencia que se manifiesta al respecto entre los propios líderes migrantes, en cuanto a dónde ubicar la causa de los problemas que enfrenta el sector campesino del estado y las soluciones potenciales a esos problemas. Felipe Delgado, por ejemplo, identificó la sobresaturación de los mercados con productos agrícolas tradicionales como la causa de las dificultades económicas de los campesinos. Sin embargo, Delgado sugirió que esto no era simplemente consecuencia de una oferta que supera a la demanda; nos dijo en cambio que «en nuestro estado tenemos un problema año tras año, que solamente sembramos frijoles: frijoles, frijoles, frijoles. Al final del año tenemos miles y miles de toneladas de frijoles.» (entrevista con Felipe Delgado, Los Ángeles, California, 13 de noviembre de 2003). Aunque argumentaba que no hay mercado para tantos frijoles, Delgado, lejos de atribuirlo a fuerzas abstractas del mercado, apunta a un agente identificable que afecta las formas de sustento de los campesinos -el intermediario o coyote-diciéndonos: «los coyotes compran en nada el kilo de frijoles, pagando a los productores quizá 20 centavos por kilo, mientras que en el mercado lo encuentras a \$1.70 el kilo.» (Entrevista con Felipe Delgado, Los Ángeles, California, 13 de noviembre de 2003).

Haciendo eco de una opinión compartida por otros líderes migrantes de la región, la solución que encuentra Delgado a los problemas que causan los coyotes que controlan el acceso al mercado es evitarlos por completo y cambiar a una producción no tradicional, orientada a la exportación. En esta visión, la producción en invernadero es la solución preferida por dos razones: en primer lugar porque el ambiente controlado del invernadero puede ahorrar en los recursos de electri- 
cidad (costosa) y agua (escasa); y, en segundo, porque la obtención de productos no tradicionales en invernadero, como pimientos y jitomates, puede realizarse en tiempos controlados para llenar un nicho en el mercado de Estados Unidos al proveer estos productos en un periodo de dos o tres meses, cuando los competidores de Estados Unidos y del estado de Sinaloa en México ya terminaron su cosecha (entrevista con Felipe Delgado, Los Ángeles, California, 13 de noviembre de 2003). En años recientes, Zacatecas ha visto un incremento significativo en la producción de invernadero, pero, según un funcionario de la Secretaría de Desarrollo Económico de Zacatecas, «es muy difícil convertir a los productores agrícolas tradicionales en productores de invernadero» por el costo que esto implicaría -aproximadamente de un millón de dólares por hectárea de invernadero (entrevista con Robert Barker, Zacatecas, Zacatecas, 24 de junio de 2004). En consecuencia, en el momento de nuestra entrevista había apenas cerca de 20 hectáreas en el estado dedicadas a la producción de invernadero.

Otros migrantes preferirían que las preocupaciones de estos productores agrícolas tradicionales se abordaran de manera más directa. Francisco Javier González, por ejemplo, un líder de las HTAs que encabeza el brazo político de la FCZSC, el Frente Cívico Zacatecano, esperaba que se diera una solución más práctica e inmediata a las inquietudes económicas de los campesinos de Zacatecas: precios de garantía por parte del estado. Al hablar sobre lo que esperaba de la «transición democrática» que prometió el entonces candidato a la gubernatura, Ricardo Monreal en 1998, González narró una conversación que sostuvo con el entonces gobernador-electo: "yo le dijé a Ricardo, «Ricardo, si vas a hacer esto, tienes que fijar los precios del frijol, del maíz, del ganado. Para que uno pueda trabajar». Esto es «(...) de la democracia nosotros queríamos que, a los campesinos principalmente, los precios se los dijeran de una vez, para que no estuvieran peleando al último.» (Entrevista con Francisco Javier González, Norwalk, California, 13 de noviembre de 2003).

Adoptar ésta u otras acciones para responder a los intereses del sector campesino tradicional muy probablemente sea un componente necesario de cualquier recuperación económica, aun si esto se da por la resistencia de los campesinos a los planes de modernización económica que los obligaría a abandonar sus formas de vida y sus identidades culturales tradicionales, tan ligadas con la tierra. La dificultad de acceder a los campesinos y su resistencia a ser incorporados a las transformaciones económicas promovidas por el estado ha derivado en una notable ironía en el mercado de mano de obra de Zacatecas: ilos potenciales inversionistas reportan que el estado no cuenta con la suficiente mano de obra! Por ejemplo, en Jerez, uno de los municipios más poblados de la entidad, con cerca de 55,000 habitantes, inversionistas taiwaneses renunciaron en 2005 a poner un proyecto de inversión, después de que un estudio del mercado de mano de obra reveló que el municipio no contaba con la fuerza de trabajo estable que se requería, 500 empleados, que pudieran comprometerse en puestos de trabajo de tiempo completo 
y durante todo el año. Un observador político en el gobierno municipal de Jerez, durante el gobierno de Andrés Bermúdez, explicó el fracaso del municipio para atraer inversionistas, relatando la respuesta de la población a las preguntas de los investigadores del mercado de mano de obra: «la mitad de ellos decía: «sí, no mas que cuando se venga el tiempo de la siembra [yo no estaré disponible]. Y cuando se venga el tiempo del riego, pues me tengo que ir a regar. Y cuando se venga el tiempo de la cosecha, me tengo que ir a cosechar.»» (entrevista con Raymundo Carrillo, Jerez, Zacatecas, 9 de agosto de 2005).

Iskander (2005) reporta un hallazgo similar en el estado de Guanajuato, en donde las maquiladoras, financiadas por los migrantes, enfrentaban una crónica escasez de mano de obra, ya que los trabajadores, una vez entrenados, se iban hacia posiciones de mejor paga en otras regiones más tradicionales dentro de la producción textil, o desertaban por completo del mercado de mano de obra cuando recibían remesas de los parientes en el extranjero. Sin embargo, como sugiere la cita anterior, en Zacatecas la escasez de mano de obra parece estar más relacionada con el vínculo de la gente con la tierra y con el ciclo agrícola, es decir, con su resistencia a la proletarización. ${ }^{5}$

\section{La dialéctica del Estado en el discurso migrante}

El papel del Estado en el discurso migrante es complejo y aparentemente contradictorio. Como consecuencia de la profunda corrupción asociada con 71 años de gobiernos emanados del PRI, el Estado y la clase política que lo controlaba son despreciados y percibidos como la causa de las deplorables condiciones económicas que convierten a la migración en necesidad. A pesar de ello, las críticas de los migrantes hacia el Estado no se han dado por la adopción de una idolatría del mercado antiestatista. En cambio, los migrantes reconocen un papel importante y vigoroso al Estado en los esfuerzos de promoción del desarrollo en los que están involucrados. Unir esas dos visiones, ayuda a entender la detallada visión de los líderes de la FCZsC sobre el papel del Estado y sobre la lógica antiestatista de la ideología neoliberal.

Durante nuestras entrevistas, surgieron las visiones de los líderes migrantes sobre el Estado a través de sus discusiones sobre el significado e importancia de la participación de los migrantes en la generación de bienes e infraestructura públicos. La posición manifestada por nuestros entrevistados puede clasificarse en dos tipos al discutir la importancia de su participación en los diversos programas de fondos complementarios -como las distintas versiones del Programa $3 \times 1$. El primer conjunto de los migrantes señalaba su participación en estos programas

\footnotetext{
${ }^{5}$ Véase Eckstein (2001: 18) para una discusión similar respecto a la resistencia campesina en otras partes de América Latina.
} 
como parte de los esfuerzos orientados a lograr mayor reconocimiento, y ampliar los derechos de los migrantes en un contexto político en el que sus opositores afirmaban, con frecuencia, que ese reconocimiento y esos derechos no deberían ofrecérseles porque la residencia de los migrantes en el extranjero tenía como consecuencia que se desconectaran de las necesidades y deseos de los verdaderos habitantes del estado. Un segundo conjunto de migrantes adoptaba una posición alternativa centrada en las limitaciones fiscales que enfrentaba el gobierno de México, lo que lo hacía incapaz de cubrir todas las necesidades de infraestructura del país.

Como reacción a las acusaciones de estar desconectados, el primer grupo enfatizaba el carácter voluntario de las cooperaciones de los migrantes en actividades que realmente son responsabilidad del Estado. Esta posición está bien articulada -en términos notoriamente transnacionales- dentro del siguiente extracto de nuestra entrevista con Guadalupe Gómez, ex-presidente de la FCZSC, en la que responde a una pregunta acerca de la manera en que él y otros líderes se mantienen conectados con las realidades concretas en Zacatecas:

Vamos allá para enterarnos de las necesidades en diferentes comunidades y apoyamos a aquellos clubes que contribuyen con esas comunidades para obtener sus servicios por medio del Programa $3 \times 1$. Ya sabe, hablamos de servicios muy básicos que son responsabilidad del gobierno. Es responsabilidad del gobierno proporcionar agua potable, sistemas de drenaje y electricidad. Un sistema muy básico i̇cierto? Bueno, no sólo estamos haciendo eso, estamos construyendo carreteras, pavimentando las calles, estamos enriqueciendo las vidas de la gente que está allá. Y (...) no tenemos que hacerlo. Yo soy, ya sabe, ciudadano americano. Soy estadounidense iAquí voto! Así que dígame si estoy desconectado, cuando recorro todo el estado, en diferentes comunidades en donde tenemos clubes y veo todas estas necesidades. (Entrevista con Guadalupe Gómez, Santa Ana, California, 14 de mayo de 2004).

Manuel de la Cruz expresó la visión contraria al responder directamente a los argumentos de los otros líderes migrantes, en el sentido de que ellos aportan lo que de hecho es responsabilidad del gobierno:

Todo el mundo dice, «es obligación del gobierno». Pues, sí pero el gobierno tiene muchas áreas. El gobierno sería imposible venir a este lugar cuando tiene estas prioridades de aquí. Pero si tú, como organización, le dices, «yo tengo mi 33\% para hacer esta obra de aquí» cuando es un dinero que no está en México, que no está en Zacatecas, sólo que ese funcionario de gobierno esté loco pero que debe de aceptar lo que nosotros proponemos. (Entrevista con Manuel de la Cruz, Zacatecas, Zacatecas, 25 de junio de 2004).

Sin duda, estas posiciones opuestas se comprenden mejor dentro del contexto de las actuales luchas políticas por el reconocimiento de poder político de los 
migrantes, que en torno a su empoderamiento se registran últimamente en Zacatecas y en todo México. Los diferentes posicionamientos sociales y políticos de los migrantes al respecto están claramente relacionados con las estrategias retóricas que utilizan para descalificar o ensalzar al migrante y al gobierno. Por ello, no hay que sorprenderse de que los migrantes que mantienen fuertes vínculos con el gobierno estatal, como De la Cruz, antiguo representante oficial del gobierno de Zacatecas, se alinien en la defensa del Estado como quien hace lo mejor posible con los limitados recursos con que cuenta; mientras que líderes de los migrantes, como Lupe Gómez y sus aliados, luchen por alcanzar el poder político, al tiempo que conservan su autonomía respecto al gobierno, por lo que mantienen la postura contraria.

No obstante, el análisis de estas diferentes visiones nos ofrece algo más que una simple demarcación de lealtades fundamentales en las batallas por el poder político de los migrantes. A pesar de los desacuerdos de corte político entre las diferentes posiciones, las representaciones de los migrantes en torno al significado de la participación de éstos en el Programa $3 \times 1$ comparten una concepción básica del papel fundamental del Estado para proporcionar bienes colectivos y promover mejoras en las formas de vida de la población. Aunque esta visión no resulta totalmente novedosa, ni siquiera en la era neoliberal, esta interpretación compartida es de la mayor importancia para nuestra comprensión de la política neoliberal, sobre todo en aquellos casos en que el Estado se considera capaz de extenderse profundamente en la esfera de la producción, ámbito semi-sacro de la ideología neoliberal del que se supone ya ha salido y dejado al dinamismo privado del mercado.

Esta visión ampliada del Estado tanto en la provisión de los bienes públicos e infraestructura, como en la producción, constituye un componente clave del discurso migrante sobre las remesas y el desarrollo. Al respecto, FCZsC activista Martha Jiménez expresa una visión relativamente radical del papel del Estado para facilitar la transición hacia proyectos productivos sustentables y socialmente justos:

Si somos capaces de lograr la transición para crear los proyectos productivos, podremos hacer que la gente se quede allá por más tiempo (...) Si el gobierno mexicano nos ayuda a crear proyectos realmente sustentables que puedan generar empleos, podremos hacerlo (...) Haremos que el gobierno mexicano, a través de la Secretaría de Economía, genere los medios necesarios en donde, si quiero tener una maquiladora que trate justamente a la gente y pague buenos salarios, pueda tenerla. (Entrevista con Martha Jiménez, Los Ángeles, California, 24 de marzo de 2005).

Ciertamente, esta visión está lejos del optimista discurso neoliberal, según el cual el promover la competencia entre los proveedores de servicios de envío de remesas y dar acceso a los migrantes a las instituciones financieras formales, 
desatará de una buena vez las reprimidas energías empresariales de los migrantes y hará llegar el desarrollo a sus comunidades de origen. En la visión de los migrantes, parece que el Estado debería desempeñar un papel fundamental, de hecho un papel ampliado, en la economía.

Sin duda alguna existen diferentes opiniones de lo que significa que el gobierno ayude a los migrantes para generar proyectos sustentables y crear los medios necesarios para que esos proyectos desemboquen en justicia y salarios adecuados para los empleados. Según lo describe Efraín Jiménez, director filantrópico de la FCZSC, cuyo trabajo es pagado con fondos de la Fundación Rockefeller, parte de la visión de los migrantes incluye la participación directa de los gobiernos estatal y federal en el financiamiento de los proyectos productivos: «mi trabajo es encontrar la manera de persuadir a nuestro gobierno de igualar la magnitud de nuestra inversión en ciertos proyectos.» (Entrevista con Efraín Jiménez, 13 de marzo de 2004). De hecho, las metas de Jiménez van más allá. He aquí de qué modo explicó el razonamiento detrás de su propuesta de campaña, como parte de la planilla perdedora en la lucha por la presidencia de la FCZSC en 2004, para crear un programa de $4 \times 1$ que incluiría la participación del gobierno de Estados Unidos:

Lo que les diría es: si quieren detener la inmigración, en vez de gastar millones de dólares en construir esa cerca enorme (...) están tratando de detener a personas inteligentes, que van a encontrar alguna manera de superar la cerca. Ustedes no están tratando de detener vacas (...) Encontraremos alguna manera porque somos inteligentes. Así que en vez de gastar esos millones de dólares en esas cercas que nos separan, más de lo que ya estamos ì por qué no gastar esos millones de dólares para generar empleos en México? (Entrevista con Efraín Jiménez, 13 de mayo de 2004).

\section{CONCLUSIÓN}

Volviendo a los temas teóricos planteados anteriormente żqué ofrece este análisis para la comprensión de los aspectos políticos y culturales de la migración transnacional? ¿Qué importancia teórica tiene la discordancia entre la concepción que tienen los migrantes del desarrollo impulsado por quienes emigraron y el discurso oficial del desarrollo basado en las remesas?

Como muestra mi análisis de los momentos discursivos centrales de la construcción que hacen los propios migrantes de la relación entre las remesas y el desarrollo, el compromiso de colaboración de la FCZsc con los representantes oficiales del discurso del desarrollo impulsado por las remesas, representa algo completamente distinto de la cooptación plena. Hay tres puntos principales de divergencia que sirven para contrarrestar cualquier lectura simplista de esta forma de política de colaboración como simple cooptación:

En primer lugar, en la visión de los líderes de la FCZSC, la migración es a la vez un proceso económico y cultural. Esta perspectiva contrasta notablemente con el 
modelo altamente economicista del discurso de las remesas como impulsoras del desarrollo, que ve a la migración como consecuencia de cálculos racionales individuales, frente a los factores económicos estructurales de expulsión y atracción. En segundo lugar, la visión de los migrantes de las causas del subdesarrollo en Zacatecas es mucho más compleja que la percepción del modelo neoliberal. Estas causas no se atribuyen simplemente a la falta de capital y a mercados financieros incompletos, ya que los migrantes hacen énfasis en los obstáculos existentes en el contexto local para lograr oportunidades viables de inversión y el desarrollo económico sustentable. Finalmente, en contraste con el silencio total del discurso oficial de las remesas como impulsoras del desarrollo y sobre el papel del Estado en el proceso de desarrollo regional, los líderes migrantes sí tienen una posición al respecto. Para ellos, el Estado puede ser la principal causa de las condiciones económicas que generan la migración, pero esto lo atribuyen al secuestro del Estado por parte de una clase política corrupta y no a la naturaleza del propio Estado. De hecho, los líderes migrantes creen que éste debe jugar un papel fundamental no sólo en el financiamiento de los bienes e infraestructura públicos que haga posible la inversión privada en Zacatecas, sino también como un socio clave en el ámbito de la producción.

El rechazo a la idea de que la política de desarrollo impulsado por los migrantes sea una sumisión a los dictados del discurso hegemónico de la globalización neoliberal, no debe llevarnos a valorar en exceso la resistencia y las oposiciones de los líderes migrantes zacatecanos. Como ha señalado recientemente Sarah Radcliffe (2005), las protestas directas y el rechazo coordinado del neoliberalismo en América Latina (y en el mundo entero, se podría añadir) están «severamente comprometidas y quizá reduzcan su probabilidad en el futuro inmediato» (Radcliffe, 2005: 328). No obstante, frente a estas intimidantes circunstancias todavía encontramos individuos, organizaciones colectivas e incluso algunos gobiernos de la región que participan en una miríada de «disputas, reelaboraciones y negociaciones con el neoliberalismo» (Radcliffe, 2005: 328).

Precisamente dentro de esa constelación de acomodo y resistencia al proyecto neoliberal hegemónico podemos ubicar adecuadamente las prácticas de los líderes migrantes zacatecanos: no pueden articular una alternativa plenamente desarrollada frente al modelo dominante, aunque los proyectos orientados al desarrollo que estos promueven y el papel que reservan a un Estado activo e intervencionista en la promoción de los mismos, representa una desviación importante respecto a la legitimación del discurso del neoliberalismo.

La forma que toma el compromiso político que han emprendido los migrantes zacatecanos con el Estado mexicano, y la comunidad filantrópica internacional, subraya la importancia de la herencia continuada de los regímenes y estructuras políticas del pasado. Estas secuelas históricas, aparentemente no se pueden hacer un lado con facilidad al imponerse el nuevo modelo económico. En el contexto del modelo político-económico dominante, las élites políticas pueden realizar intentos por promover una nueva forma neoliberal de ciudadanía de mercado, 
como han sostenido Schild (1998), Goldring (2001) y Harvey (2001), en la cual los ciudadanos habrían de mirar al mercado y no a los estados, como portador último de los bienes y protecciones sociales. Sin embargo, las concepciones de los ciudadanos transnacionales emergentes estudiados aquí en cuanto al papel y las responsabilidades del Estado para garantizar el bienestar general, no se liberan fácilmente de las ataduras a las formas previas de representación y legitimidad. Ello sugiere la necesidad de apartarse de las afirmaciones generalizadoras de quienes verían los cambios económicos formales forjados por el neoliberalismo como generadores también de cambios socioculturales como «una renovada fe en el mercado» (Portes, 1997: 238) o un desmantelamiento de los sentimientos nacionalistas tradicionales y de la resistencia a la dominación imperial.

Obviamente, los migrantes no tienen aspiraciones de regresar al pasado corrupto y semiautoritario del gobierno unipartidista en México, pero tampoco es fácil que las nuevas élites políticas con su aparente alejamiento del nacionalismo revolucionario, los encaminen hacia el proyecto acomodaticio y neoliberal de la integración de Norteamérica. La continuación de la desconfianza popular frente a las élites gobernantes tiende a predisponer a los migrantes y a los ciudadanos en general, hacia un sano escepticismo frente a las exaltadas promesas de políticos y planificadores. Al final de cuentas, los líderes migrantes no son las víctimas de un discurso despolitizador en el que las remesas figuran como impulsoras del desarro1lo, pero tampoco son recipientes inertes de los cambios culturales amplios y difundidos que se han suscitado por las reformas neoliberales desde arriba. Los líderes migrantes son agentes históricos que viven y respiran y son capaces de ver y actuar políticamente.

Al reconocer esta capacidad de los líderes migrantes de actuar como agentes políticos en esta era de hegemonía ideológica neoliberal, no debemos pasar por alto el hecho de que ellos, aun cuando comparten una misma posición de clase, se dividen por numerosos vectores de desigualdad. Los anclajes sociales en la FCZsC se hacen más evidentes en las líneas de batalla trazadas en sus luchas por el reconocimiento de su poder en Zacatecas, en donde los migrantes se presentan divididos por las diferentes ideologías políticas, las lealtades partidistas o no partidistas, así como por una orientación anti-partidista en un panorama político cambiante. Los líderes migrantes de la FCZSC difieren también en relación con otras divisiones sociales como el género o la clase social. El género, por ejemplo, es un elemento estructurante en las HTAs, al asignarles a los varones los roles de liderazgo activo y limitando a las mujeres a posiciones de apoyo más pasivas (Goldring, 2001a y 2001b); en consecuencia, el liderazgo migrante es casi exclusivamente un ámbito masculino, a pesar de la incesante lucha de unas cuantas mujeres activistas. A su vez, las divisiones a partir de los antecedentes de clase social en Zacatecas, tienden a manifestarse en relación con los patrones de adecuación o resistencia a la estructura emergente de poder y las alineaciones partidistas. Estas subdivisiones sustantivas y sus distinciones sociales dentro de las HTAs y la FCZSC muestran claramente algunas de las limitaciones de las nociones esencialistas de migrante colectivo o comu- 
nidad transnacional, y nos obligan a ver los espacios sociales transnacionales como arenas de disputa, espacios de significados en conflicto y en donde conviven proyectos políticos diversos.

Aun cuando estas diferencias sociales y divisiones políticas, que atraviesan el espacio social de la FCZSC y la formación social transnacional zacatecana, constituyen importantes obstáculos para los esfuerzos de canalizar las energías políticas de los migrantes por rumbos radicalmente democráticos, estas divisiones no son completamente irreconciliables. Estas identidades sociales, actualmente en competencia, pueden verse como elementos capaces de crear proyectos políticos más amplios, al ofrecer una alternativa conciente a la hegemonía del actual modelo económico neoliberal, así como a la estratificación tradicional por sexo que para amplias capas de la sociedad mexicana ofrece pocas oportunidades.

Este es, por supuesto, el dilema político central de nuestra época, encontrar los medios para unir cadenas de equivalencia a través de la multiplicidad de diferencias y antagonismos y, por ende, comenzar a formar coaliciones políticas capaces de ofrecer nuevas posibilidades hegemónicas (Laclau y Mouffe 1985). Pero hasta que la construcción de estas coaliciones se convierta en un proyecto político explícito, expresiones como el migrante colectivo que proponen una identidad migrante unificada y una agencia colectiva ya emergente, sólo sirven para ocultar las dificultades inherentes en esta tarea y desviar la atención de su construcción real.

\section{BIBLIOGRAFÍA}

BADA, Xóchitl (2003), «Mexican Hometown Associations», Citizen Action in the Americas, núm. 5.

BANCO DE MÉXICO (2007), «Remesas Familiares», disponibleen http://www.banxico.org.mx/ SieInternet/consultarDirectorioInternetAction. do? accion $=$ consultarCuadroAnaliti co\&idCuadro $=$ CA11\&sector $=1 \&$ locale $=$ es.

Burawoy, Michael (2000), «Introduction: Reaching for the Global», en Burawoy, Michael, et. al. (editores), Global Ethnography: Forces, Connections, and Imaginations in a Postmodern World, Berkeley y Los Angeles, University of California Press, pp. 1-40.

Moufre, C. (1979) Gramsci and Marxist Theory, Routledge.

Delgado Wise, Raúl (2006), "Migration and Imperialism: The Mexican Workforce in the Context of NafTA», Latin American Perspectives, vol. 33, núm. 2, pp. 33-45.

Delgado Wise, Raúl y Héctor Rodríguez Ramírez (2001), «The Emergence of Collective Migrants and Their Role in Mexico's Local and Regional Development», Canadian Journal of Development Studies, vol. 22, núm. 3, pp. 747-764.

Delgado Wise, Raúl, Humberto Márquez y Héctor Rodríguez (2004), "Organizaciones transnacionales de migrantes y desarrollo regional en Zacatecas", Migraciones Internacionales, revista de El Colegio de la Frontera Norte, 2 (4): 159-181.

(2002), «El Nuevo Panorama de la Migración Internacional y sus Potencialidades para el Desarrollo Regional en Zacatecas», El Norte de Todos: Migración y Trabajo en Tiempos de Globalización, en Arroyo Alejandre, Jesús, Alejandro I. Canales Cerón, y Patricia 
Noemí Vargas Becerra (editores), Guadalajara, Los Ángeles y México, Universidad de Guadalajara, Ucla Program on Mexico, Profmex, Juan Pablos Editor, pp. 209-237.

DolHinow, Rebecca (2005), "Caught in the Middle: The State, NGos, and the Limits to Grassroots Organizing Along the US-Mexico Border», Antipode, vol. 37, núm. 3, pp. 558-580.

ECKSTEIN, Susan (2001), «Epilogue. Where Have All the Movements Gone? Latin American Social Movements at the New Millennium», en Eckstein, Susan (editora), Power and Popular Protest: Latin American Social Movements, (2nd Ed.), Berkeley y Los Ángeles, University of California Press, pp. 351-406.

García y Griego, Larry Manuel (1988), «The Bracero Policy Experiment: U.S.-Mexican Responses to Mexican Labor Migration,1942-1955», Tesis doctoral, Los Ángeles, University of California.

GoldRING, Luin (2001a), «The Gender and Geography of Citizenship in Mexico-U.S. Transnational Spaces», Identities: Global Studies in Culture and Power, núm. 7, pp. 501-537.

(2001b), «Disaggregating Transnational Social Spaces: Gender, Place and Citizenship in Mexico-US Transnational Spaces», en Pries, Ludger (editor), New Transnational Social Spaces, Londres y Nueva York, Routledge, pp. 59-76.

(2002), «The Mexican State and Transnational Organizations: Negotiating the Boundaries of Membership and Participation", Latin American Research Review, vol. 37, núm. 3, pp. 55-99.

(2004), «Family and Collective Remittances to Mexico: A Multi-dimensional Typology», Development and Change, vol. 35, núm. 4, 799-840.

Guarnizo, Luis Eduardo (1998), «The Rise of Transnational Social Formations: Mexican and Dominican State Responses to Transnational Migration,» Political Power and Social Theory, núm. 12, pp. 45-94.

Guarnizo, Luis Eduardo y Michael Peter Smith (1998), «The Locations of Transnationalism», Transnationalism From Below, en Smith, Michael Peter and Luis Eduardo Guarnizo (editores), New Brunswick, N.J., Transaction, pp. 3-34.

Hall, Stuart (1996), «The Problem of Ideology: Marxism Without Guarantees», en Morley, David y Kuan-Hsing Chen (editores), Stuart Hall: Critical Dialogues in Cultural Studies, London, New York, Routledge, pp. 25-46.

Harvey, Neil (2001), "Globalisation and Resistance in Post-Cold War Mexico: Difference, Citizenship and Biodiversity Conflicts in Chiapas», Third World Quarterly, vol. 22, núm. 6, pp. 1045-1061.

IsKander, Natasha (2005), «Social Learning as a Productive Project: Zacatecas and Guanajuato's Cautionary Tales», paper presented at «International Conference on Migration, Remittances and the Economic Development of Sending Countries», Marrakech, Marruecos, febrero, pp. 23-25.

KeARnEY, Michael (1991), «Borders and Boundaries of the State and Self at the End of Empire», Journal of Historical Sociology, vol. 4, núm. 1, pp. 52-74.

LaClau, Ernesto y Chantal Mouffe (1985), Hegemony and Socialist Strategy: Towards a Radical Democratic Politics, Londres, Nueva York, Verso.

Lanly, Guillaume and M. Basilia Valenzuela Varela (2004), Clubes de migrantes oriundos mexicanos en los Estados Unidos: la política transnacional de la nueva sociedad civil migrante, Zapopan, Jalisco, Universidad de Guadalajara, Centro Universitario de Ciencias Económico Administrativas.

70 SEGUNDO SEMESTRE 2007

MIGRACIÓN Y DESARROLLO 
Lozano Ascencio, Fernando (2004), «Current Trends in Migrants» Remittances in Latin America and the Caribbean: And Evaluation of the Social and Economic Importance», Paper presented at «Migrants» Remittances: An Alternative for Latin America and the Caribbean?», Caracas, Venezuela, Julio, pp. 26-27.

Lozano, F. y Fidel Olivera Lozano (2005), "Impacto económico de las remesas en México: un balance necesario" Cuernavaca, Morelos. Seminario Internacional Problemas y Desafíos de la Migración y el Desarrollo en América, 7-9 de abril <http://www.migracionydesarrollo.org >.

Márouez Covarrubias, Humberto (2006a), "Controversias en el Desarrollo Económico Local Basado en las Remesas de los Migrantes», Análisis Económico, vol. 21, núm. 47, pp. 307-330.

(2006b), «El desarrollo participativo transnacional basado en las organizaciones de migrantes», Problemas del Desarrollo, vol. 37, núm. 144, pp. 121-144.

(2006c), «El influjo de la remesa participativa en las zonas de alta migración internacional», Epikeia: Derecho y Política, núm. 2, disponible en www.leon.uia.mx/ epikeia.

MarTíneZ, Jesús (1998), «In Search of our Lost Citizenship: Mexican Immigrants, the Right to Vote, and the Transition to Democracy in Mexico», Working Paper núm. 20, Santa Cruz, Chicano/Latino Research Center, University of California.

Moctezuma Longoria, Miguel (2002), «Los Migrantes Mexicanos en los Estados Unidos y la Inversión Productiva en México», Migraciones Internacionales, vol.1, núm. 3, pp. 149-162.

(2003), «The Migrant Club El Remolino: A Bi-national Community Experience», in Confronting Globalization: Economic Integration and Popular Resistance in Mexico, en Wise, Timothy A., Hilda Salazar y Laura Carlsen (editores), Bloomfield, Kumarian Press, pp. 195-210.

(2005), «Morfología y Desarrollo de las Asociaciones de Migrantes Mexicanos en Estados Unidos. Un Sujeto Social y Política Extraterritorial», Migración y Desarrollo, vol. 5, pp. 59-85.

Multilateral InVestment Fund (2005), «Remittances 2004: Transforming Labor Markets and Promoting Financial Democracy», Paper presented at «Sending Money Home: the 2004 Map of Remittance Flows to Latin America", marzo 24.

Partnership for Prosperity (2002), «Creating Prosperity Through Partnership», disponible en http://www.ustreas.gov/press/releases/reports/200251420452981182.pdf.

Petras, James (1997), "Imperialism and NGOs in Latin America», Monthly Review, vol. 49, núm. 7, pp. 10-33.

y Henry Veltmeyer (2001), Globalization Unmasked: Imperialism in the 21st Century, Halifax, Nueva Escocia, Nueva York, Fernwood Pub., Zed Books.

PorTes, Alejandro (1997), «Neoliberalism and the Sociology of Development: Emerging Trends and Unanticipated Facts», Population and Development Review, vol. 23, núm. 2, pp. 229-259.

(1998), "Globalization From Below: The Rise of Transnational Communities», Working Paper WPTC 98-01, Transnational Communities Programme, University of Oxford. 
Radcliffe, Sarah. (2005), "Neoliberalism As We Know It, But Not in Conditions of its Own Choosing: A Commentary", Environment and Planning A, vol. 37, núm. 2, pp. 323-329.

Rivera-Salgado, Gaspar y Luis Escala Rabadán (2004), «Collective Identity and Organizational Strategies of Indigenous and Mestizo Mexican Migrants", Indigenous Mexican Migrants in the United States, en Fox, Jonathan y Gaspar Rivera-Salgado (editores), La Jolla, Center for U.S.-Mexican Studies, UC San Diego, pp. 145-178.

Rivera-Salgado, Gaspar, Xóchitl Bada y Luis Escala Rabadán. (2005), «Mexican Migrant Civic and Political Participation in the U.S.: The Case of Hometown Associations in Los Angeles and Chicago», Ponencia presentada en "Mexican Migrant Social and Civic Participation in the United States», Woodrow Wilson International Center for Scholars, Washington, D.C.,

Rodríguez, Néstor (1996), «The Battle for the Border: Notes on Autonomous Migration, Transnational Communities and the State», Social Justice, vol. 23, núm. 3, pp. 21-37. SCHILD, Verónica (1998), «Market Citizenship and the «New Democracies»: The Ambiguous Legacies of Contemporary Chilean Women's Movements», Social Politics, vol. 5, núm. 2, pp. 232-249.

SMrTH, Michael Peter (2001), Transnational Urbanism: Locating Globalization. Oxford, Malden, Mass., Blackwell.

TerRY, Donald F. y Steven R. Wilson (2005), Remesas de inmigrantes: moneda de cambio económico y social, Washington, D.C., Banco Interamericano de Desarrollo.

YAWorsky, William (2005), «At the Whim of the State: Neoliberalism and Nongovernmental Organizations in Guerrero, Mexico», Mexican Studies, Estudios Mexicanos, vol. 21, núm. 2, pp. 403-427. 